\title{
Construcción de identidad en jóvenes de Manizales vinculados a barras de fútbol*
}

\author{
Construction of identity in young people from Manizales \\ belonging to soccer fan groups
}

Construção de identidade em jovens de Manizales vinculados a torcidas organizadas de futebol

Recibido el 3 de octubre de 2016. Aceptado el 14 de marzo de 2017

\author{
Nataly Giraldo Higuita** \\ Colombia \\ Jaime Alberto Restrepo Soto*** \\ Colombia
}

\section{Resumen}

Para citar este artículo:

Giraldo Higuita, Nataly y

Restrepo Soto, Jaime Alberto

(junio, 2017). Construcción

de identidad en jóvenes de

Manizales vinculados a barras de fútbol. Ánfora, 24(42), 165

187. Universidad Autónoma de

Manizales. ISSN 0121-6538.
Objetivos: describir el proceso de construcción de la identidad de jóvenes adscritos a barras de del fútbol, a través de las categorías de identidades, vinculaciones, rituales y símbolos que emergen de sus prácticas individuales y colectivas. Metodología: investigación cualitativa de orden descriptivo y etnográfico, en la que se implementaron técnicas de grupo focal y entrevista. La información se registró en diarios de campo, cuya unidad de análisis se operó en las categorías de género, cuerpos,

\footnotetext{
* El artículo se desprende de una de las categorías del Proyecto de Investigación y Desarrollo "Fútbol y Ciudad", como trabajo de grado para optar al título de Psicóloga y en el que el segundo autor se desempeñó como asesor. Este proyecto está adscrito al grupo de investigación "Psicología del Desarrollo" de la Facultad de Ciencias Sociales Humanas de la Universidad de Manizales. Se inició en mayo de 2013 y terminó en mayo de 2016.

** Psicóloga. Universidad de Manizales. Asistente de investigación del proyecto "Fútbol y Ciudad". Correo electrónico: psiconatg@gmail.com

*** Doctor en Ciencias Sociales Niñez y Juventud. Magister en Educación y Desarrollo Humano. Psicólogo, Especialista en Educación Sexual. Profesor de la Universidad de Manizales. Correo electrónico: jaimea@ umanizales.edu.co
} 
subjetividades y movimientos, identidades y vinculaciones, estigmas y emblemas, territorialidades, rituales y simbología. El análisis de la información se realizó a través de la construcción de matrices (agregados, iterativos y hallazgos). Resultados: se evidenció un índice alto de filiación de los jóvenes a las barras y que la fidelidad y la violencia son sus principales características. También se verificó la construcción de su identidad individual y colectiva en torno a la ideología y los componentes de la cultura barrista; además, se constató el fervory la pasión que provocaun partido de fútbol en las barras. Conclusiones: existen particularidades, en concordancia con aportes de otras investigaciones, que permitieron notar la importancia y los lazos afectivos que construyen los jóvenes de las barras de fútbol al compartir ideologías, rituales y símbolos alusivos a sus equipos.

Palabras clave: Identidad cultural; Barras; Fútbol; Jóvenes.

\section{Abstract}

Objective: to describe the process of identity construction in young people belonging to soccer fan groups through the following categories: identities, linkages, rituals and symbols that emerge from their individual and collective practices. Methodology: a qualitative research with a descriptive and ethnographic scope was conducted. Focus groups and interviews were implemented as techniques of the study. The information was recorded in field log, whose unit of analysis was operated in the categories of gender, bodies, subjectivities and movements, identities and linkages, stigmas and emblems, territoriality,ritual rhythms, as well as symbolism. The dataanalysiswas carried out through the construction of matrices (aggregates, iterative processes and findings). Results: a high young people affiliation rate to fan groups was evidenced; fidelity and violence were the main characteristics found. Their individual and collective identity construction regarding ideology and components of the soccer fan groups' culture was also verified. In addition, the fervor and passion that a soccer match causes in people belonging to these groups was confirmed. Conclusions: there are particularities, in accordance with other research contributions, that led to note the importance of emotional ties built by young people belonging to soccer fan groups when they share ideologies, rituals and symbols alluding to their teams.

Keywords: Cultural identity; Fan groups; Soccer; Young people.

\section{Resumo}


Objetivo: descrever o processo de construção da identidade de jovens pertencentes a torcidas organizadas de futebol, através das categorias de identidades, vinculações, rituais e símbolos que emergem de suas práticas individuais e coletivas. Metodologia: pesquisa qualitativa de ordem descritivo e etnográfico na que foram implementadas técnicas de grupo focal e entrevista. A informação foi registrada em diários de campo, cuja unidade de análise foi operada nas categorias de gênero, corpos, subjetividades e movimentos, identidades e vinculações, estigmas e emblemas, territorialidades, rituais e simbologia. A análise dos dados foi realizada utilizando a construção de matrizes (agregados, interativos e achados). Resultados: evidenciou-se uma alta taxa de filiação de jovens nas torcidas organizadas e achou-se que a lealdade e a violência são as suas principais caraterísticas. Também se verificou a construção de sua identidade individual e coletiva em torno à ideologia e aos componentes da cultura das torcidas; Além disso, constatou-se o fervor e a paixão que provocam um jogo de futebol nas torcidas. Conclusões: existem particularidades, de acordo com contribuições de outras pesquisas, o que permitiu observar a importância e os laços afetivos que constroem os jovens das torcidas organizadas ao compartilhar ideologias, rituais esímbolos alusivos a suas equipes.

Palavras-chave: Identidade cultural; Torcidas organizadas; Futebol; Juventude. 


\section{Introducción}

El fútbol más que un deporte, se ha convertido en un suceso emotivo e identitario para muchas personas en el mundo. Como afirma Galeano (1995):

En el fútbol, ritual sublimación de la guerra, once hombres de pantalón corto son la espalda del barrio, la ciudad o la nación. Estos guerreros sin armas ni corazas exorcizan los demonios de la multitud, y le confirman la fe: en cada enfrentamiento entre dos equipos, entra en combate viejos odios y amores heredados de padres a hijos (p.18).

En palabras de Panzeri (2011) “(...) el fútbol absorbe la atención pasajera o permanente de un porcentaje de población mundial como difícilmente alguna de las otras atracciones humanas alcance a hacerlo en forma separada" (p.43). Además, menciona Vélez (2011) que:

Para sus seguidores en todo el mundo, es deporte y juego al mismo tiempo, es pasión universal e identidad local; él es lenguaje común y metáforas del ser. Si bien una lectura como una forma de entendimiento entre los pueblos y una fiesta mundial en un lenguaje igual para todos, lo cual sugeriría la idea de un planeta sin fronteras, él es igualmente fuente de enemistades y odios vernáculos entre amigos o entre fanáticos de un mismo país, una misma ciudad o una parentela. $\mathrm{El}$ fútbol genera incomprensiones que, en ocasiones, se tornan en violencia y brutalidad sin límites, expresadas en el plano individual o en el colectivo (p. 69).

Ahora, el fenómeno del barrismo surgió con mayor magnitud en países europeos y en Latinoamérica. Colombia heredó esta tradición de barras de otros países e incorporó al fútbol la conformación de grupos con ciertas particularidades, rituales, movimientos e identidades que los destacan y diferencian de otros grupos sociales. "La barra es una agrupación de hinchas que tiene un orden social complejo, difícil de aprehender en términos concluyentes por la dinámica de los segmentos y los actores sociales que la componen" (Moreira, 2007, p. 4). En Manizales, Caldas (Colombia) existen grupos de barristas que animan equipos de fútbol como el Once Caldas y el Atlético Nacional. La mayoría de estos jóvenes viven su afición y pasión de acuerdo con el equipo al que pertenecen; observándose similitudes entre ellos sin importar su adhesión, como comentan Londoño y Pinilla (2009):

Las prácticas barristas se dan en un contexto deportivo en el cual el fútbol está constituido como un fenómeno social que moviliza multitudes en el mundo, y 
despierta el sentimiento de miles de hinchas que siguen y alientan a su equipo en escenarios locales, nacionales o internacionales (p. 74).

Además, sobre el fútbol, también se afirma que

Este fenómeno nació en Europa, donde los aficionados violentos son reconocidos como fenómeno de sociedad y designados con la palabra inglesa hooligans. El hooliganismo se ha asociado, en principio, a las diferencias sociales, a la integración de inmigrantes, a los conflictos entre clases, a los nacionalismos y en los últimos años, a ideologías xenófobas y neonazis. El hooliganismo solo tiene relación con el fútbol. Tiene lazos directos con dinámicas sociales (Clavijo, 2010, p. 16).

Así pues, el fútbol transciende en quienes integran este tipo de grupos sociales, a modo de objeto de sublimación e identidad; por eso, de acuerdo con Villena (2002):

El fútbol podría considerarse, entonces, un escenario ritual que hace posible obviar, en el plano simbólico, las diferencias estructurales entre los individuos y propicia su inmersión en un espacio de communitas, de comunión entre quienes usualmente se encuentran separados estructuralmente por diferencias de rol y status (Villena, 2002, p. 10).

Por otro lado, hay ciertas tendencias a movilizar a los jóvenes que pertenecen a las barras que los identifican y distinguen de otros movimientos sociales; éstas se constituyen, como muestra el contexto, en una organización estructurada con prácticas alusivas en torno al fútbol y al equipo que les genera pasión. En cuanto a las características de las "barras", para Garriga (citado por Castaño y Uribe 2014):

Tienen tres cualidades distintivas que los diferencian y los aglutinan. La primera es la fidelidad; estos simpatizantes afirman ser aquellos que a pesar de las condiciones desfavorables asisten a los partidos, sin importar si la adversidad tiene facetas deportivas, climáticas o de largas distancias. La segunda cualidad es el fervor; según sus concepciones, son los únicos espectadores que durante todo el encuentro deportivo saltan y cantan, alentando a su equipo sin importar si éste pierde, gana o empata. La tercera tiene que ver con las prácticas violentas; según este mismo autor, los miembros de barra consideran que ponen a disposición del honor del club sus tendencias violentas para no ser ofendidos por los adversarios; los miembros de la barra consideran que subyacente al encuentro futbolístico se 
dirimen cuestiones de honor y prestigio del club y de sus simpatizantes, que sólo pueden debatirse en el plano de los enfrentamientos agresivos y violentos (p. 16).

Estas características -entre ellas, la fidelidad, como una de las fundamentalesdan cuenta del carácter de la filiación de los jóvenes a las barras; además, la violencia y la rebeldía, son una manera común de definir a los jóvenes que pertenecen a estas barras. El fervor, también es otro de los factores que mueven la pasión en un partido de fútbol; incluso una simple bandera, para ellos significa "más que sus vidas". Así, los colectivos conformados por los jóvenes barristas no sólo se definen en torno a la violencia, sino también a una razón de ser en el proceso de la construcción de su identidad individual y colectiva, ya que los jóvenes comparten la ideología y demás elementos que hacen parte de la cultura barrista. "Las prácticas de los jóvenes son entendidas como las formas de acción propias a partir de las cuales configuran y viven su cotidianidad al hacer parte de una comunidad política en construcción” (Londoño y Pinilla, 2009, p. 75).

Dichos aspectos llevan a plantearse interrogantes sobre cuáles son las concepciones subjetivas e intersubjetivas de estos jóvenes; qué los mueve a pertenecer y generar pertenencia a un grupo social, incluso, desdibujando a veces su pasión hacia el fútbol y su equipo, para crear una filiación más intensa con su barra y grupo de amigos. Así pues, de lo anterior se generan preguntas como ¿qué tiene dicho entorno social para convocar a tantos jóvenes a identificarse con una camiseta, un color, una bandera, el consumo de sustancias y otras prácticas y símbolos del mundo barrista? ¿Es, Entonces, este grupo social, que adopta características independientes del equipo de fútbol, una tribu urbana?

Para responder tales interrogantes hay que precisar que una tribu urbana se refiere a un grupo de personas, usualmente jóvenes que comparten aficiones o ideologías y lo demuestran por medio de signos externos que los unifican; esto, va más allá del cuestionamiento anterior y lleva a preguntarse por la identidad social de estos jóvenes. Tajfel (citado por Javaloy, 1993) la define como "como aquella parte del auto-concepto de un individuo que deriva del conocimiento de su pertenencia a un grupo social junto con el significado valorativo y emocional asociado a dicha pertenencia" (p. 280). Desde esta perspectiva, cabe destacar la importancia y el valor emocional que canalizan los jóvenes hacia un equipo de fútbol y sobre todo hacia la barra a la cual pertenecen, configurando de este modo: La identidad social y movimientos sociales, que se originan en el entorno que los rodea, el hecho de vivir en un barrio o un sector donde exista un 
"parche"1 o un grupo de jóvenes que sigan un equipo de fútbol, moviliza a otros jóvenes a que le den un valor similar a las mismas subjetividades que tienen con respecto a la ciudad, el equipo de su ciudad y el barrio en el que habitan.

Prácticas como usar atuendos alusivos al equipo, cantar, saltar, participar en actividades en pro del crecimiento de la barra, entre otras, hacen que los jóvenes encuentren un sentido y soporte para su existencia; además, se agrega a los símbolos y prácticas un valor sentimental y emocional que crece y se nutre a medida que participan en dicho grupo, en el que comparten ideas, pensamientos y sentimientos ligados a un mismo propósito; esto, se ha evidenciado en grupos conformados por jóvenes, como lo afirma Clavijo (2010):

Las barras como grupos de muchachos cuya edad varía entre 12 y 15 años, fanáticos de los equipos profesionales de fútbol, que manifiestan su gusto por este deporte y por sus equipos, mediante formas características como los cantos y las arengas, que llevan mensajes de violencia y también por acciones de agresión física dentro y fuera de los estadios contra los hinchas (pp. 15-16).

La construcción de identidad de jóvenes barristas va ligada a pautas y comportamientos singulares que se manifiestan en los rituales y símbolos que se expresan en los sitios de socialización; por ejemplo, el estadio es el principal recinto de congregación seguido del barrio en el que viven y otros lugares en los que conforman los llamados "parches". Así lo indican García y López (2000), "la barra empezó con un grupo de amigos que llevaban la misma ideología de cantar y saltar durante todo el partido, así como de tirar rollos y quemar pólvora" (p. 20). Muestra esto que dichos jóvenes comparten lugares, espacios de socialización, símbolos y rituales que los caracterizan, transmitiendo imágenes y señales correspondientes al "ser barrista" y al mundo del fútbol y del equipo que siguen por medio de intersubjetividades que demuestran la igualdad ideológica de sus pensamientos e ideales, además de evidenciar una necesidad de reconocerse como una organización estructurada y jerárquica, como se observó en los espacios donde se realizó esta investigación. Además, la filiación, el sentimiento de "familia" que adopta la barra y los lazos de amistad que se generan a raíz de un partido de fútbol.

1 "Grupo de amigos" (Asihablamos.com, 2015)

2 Se refiere al acto de lanzar rollos papel a la cancha del estadio, haciendo alusión a la fiesta y la celebración (N. del A.)

3 Se refiere al uso de los fuegos artificiales en los partidos de futbol (N. del A.) 
De acuerdo con Scandroglio et al. (citado por Mercado, Hernández y Alejandrina, 2010):

El núcleo de la TIS ${ }^{4}$ se origina en la idea de que «por muy rica y compleja que sea la imagen que los individuos tienen de sí mismos en relación con el mundo físico y social que les rodea, algunos de los aspectos de esa idea son aportados por la pertenencia a ciertos grupos o categorías sociales.

Esto indica que no sólo el grupo social le aporta características al joven en la construcción de su identidad individual, sino que el joven también le aporta características para la conformación de dicha identidad colectiva. Ambas perspectivas, tanto lo individual desde la subjetividad como las intersubjetividades dadas en un espacio o grupo social, impactan a las personas que pertenecen a dichos grupos.

Tal como lo expone Meneses (2008) "La socialización marca pautas de comportamiento, objetivación y explicación del mundo a través de la intersubjetividad" (p.107). Esto indica además, que en dichos espacios es donde se evidencian las intersubjetividades de los jóvenes, compartiendo ideales, pensamientos, emociones y sentimientos ligados a diferentes temas que giran en torno al fútbol y las prácticas barristas, como el construir una nueva canción, crear un nuevo "trapo" o bandera, e incluso la logística para el antes, durante y después de un partido.

Turner (citado por Canto y Moral, 2005), habla acerca de identidad social autor

Un grupo social tiene lugar cuando dos o más individuos comparten una identidad social común y se perciben a sí mismos como miembros de la misma categoría social. Por lo tanto, un grupo social sería la colección de dos o más personas que, al poseer la misma identidad social, se identifican a sí mismos del mismo modo y poseen la misma definición de quiénes son, de cuáles son sus atributos y cómo se relacionan y se diferencian (p. 61).

Dicho enunciado, confirma la idea de que las personas pertenecientes a una barra de fútbol adoptan características similares que las distinguen de los miembros de grupos sociales de otro tipo, no sólo por su apariencia física, sino

\footnotetext{
4 Teoría de la Identidad Social.

5 Se refiere a la bandera del equipo de fútbol (Nota. De los Autores)
} 
también por los comportamientos, pensamientos y sentimientos que surgen al verse en las calles o en otros espacios; es decir, se diferencian tanto individual como colectivamente. "La identidad social, entonces, es un logro práctico, un proceso que puede entenderse utilizando un modelo de interjuego dialéctico de definición interna y externa, es decir, en una síntesis entre identificación grupal y categorización social” (Fernández, 2004, p. 2).

La identidad también se manifiesta en la importancia de cantar y alentar al equipo de fútbol durante un partido en el estadio, probando que "cantar, alentar y tener aguante" son que corresponden a la identidad colectiva de los barristas y se expresan en sus discursos con pertenencia por lo que aman, sus ideas y pensamientos relacionados al equipo y a la barra a la cual pertenecen.

Como se mencionó anteriormente, la mayoría de las barras atraen a la población joven que está en plena construcción de su identidad individual, razón por la cual son influenciables con facilidad por creencias, pensamientos y pautas de comportamiento atractivas a sus ideales. Con respecto a esto, los integrantes de "la hinchada" tienen usos, representaciones y consumos que los distinguen otros grupos sociales. Connerton (citado por Garriga, 2005), afirma que las prácticas y las conductas físicas están socialmente constituidas. No sólo las acciones corporales sino también las representaciones y las concepciones, no son naturales sino construidas. Ciertas acciones y conductas son muy visibles tanto en Manizales como en otras regiones del país:

Es rarísimo encontrar en Bogotá a una persona que no le guste el fútbol y no tenga una camiseta de un equipo de fútbol, o que alguien entre los 12 y los 25 años utilice una camiseta y no pertenezca a un grupo bravo (Ávila, 2008, p. 5).

El párrafo precedente da cuenta de que el fútbol mueve al colectivo y que a éste se ligan, principalmente, jóvenes quienes con sus ideales y subjetividades encuentran una razón de ser en un escudo, un color, una bandera y en un grupo de amigos o personas que piensan y se comportan igual, o que dichos pensamientos y comportamientos son atractivos para ellos.

Ahora bien, en relación con las tribus Castillo (2002) dice que "Las bandas son agrupamientos constituidos por jóvenes de entre doce y 24 años de edad. Aunque existen miembros femeninos e inclusive bandas formadas sólo por mujeres, la banda inicialmente está formada predominantemente por jóvenes varones" (p. 62). En este aspecto, se aclara aún más la postura sobre la edad de las personas que son atraídas a estos grupos colectivos en los que manejen características 
similares que las identifica, como una manera de construir su identidad a partir de elementos aportados por el contexto al que se integran.

Una explicación de esto, ofrecida por García y López (2000) es que:

Usted llega a algún lado y mira para todas partes y empieza a copiar para acoplarse al grupo. Y uno ve a algún líder y el pelado se prende de lo que hace él. Que, si lo ven fumando marihuana, entonces esos modelos se copian (p. 87).

Dichos discursos dan cuenta de la necesidad del joven a pertenecer y encontrar un lugar donde se sienta acogido e identificado, así como el compartir ideales y comportamientos, también buscan que en dicho espacio colectivo sean admitidos, respetados y normalizados. Para lograrlo imitan al grupo, sea por medio del consumo de sustancias, los cantos y la elaboración de "trapos" y banderas alusivas al equipo, considerados símbolos y rituales que identifican la identidad social barrista del grupo.

Los hinchas no están solos, piensan, se organizan y actúan como bandos. Se consideran siempre como parte de una totalidad que los trasciende, actúan como grupo en las relaciones de alianza y en las hostilidades frente a otros grupos, a otras comunidades de hinchas. Forman una comunidad sólida que se caracteriza por la misma pasión, los mismos afectos, por compartir los mismos símbolos (la misma camiseta, la misma bandera, los mismos colores, los mismos himnos) y la misma historia. Son parte de una comunidad que se identifica principalmente por las intensas relaciones de camaradería y de complicidad (Medina, 2009, p.12).

También, en la construcción de la identidad social, se hace alusión a la teoría planteada por Erickson (citado por Bordignon, 2006), y su teoría de desarrollo psicosocial, donde se encuentra el estadio de identidad versus confusión de roles:

La integración psicosexual y psicosocial de esta etapa tiene la función de la formación de la identidad personal en los siguientes aspectos: a) identidad psicosexual por el ejercicio del sentimiento de confianza y lealtad con quien pueda compartir amor, como compañeros de vida; b) la identificación ideológica por la asunción de un conjunto de valores, que son expresados en un sistema ideológico o en un sistema político; c) la identidad psicosocial por la inserción en movimientos o asociaciones de tipo social; d) la identidad profesional por la selección de una profesión en la cual poder dedicar sus energías y capacidades de trabajo y crecer profesionalmente; y e) la identidad cultural y religiosa en la que 
se consolida su experiencia cultural y religiosa, además de fortalecer el sentido espiritual de la vida (p. 56).

Teniendo en cuenta lo anterior, y considerando que la mayor parte de los integrantes de las barras se encuentran en dicha etapa del desarrollo psicosocial, existe una necesidad de identificación ideológica ligada a la identidad psicosocial como forma de hacer parte de un grupo y/o vincularse con otros que piensen igual o compartan conductas similares.

De igual forma, retomando la teoría Erickson (citado por Bordignon, 2006):

La relación social significativa es la formación de grupo de iguales, por el cual el adolescente busca la sintonía e identificación afectiva, cognitiva y comportamental con aquellos con los cuales puede establecer relaciones autodefinitorias; superar la confusión de roles; establecer relaciones de confianza, estabilidad y fidelidad; consolidar las formas ideológicas o las doctrinas totalitarias y enfrentar la realidad de la industrialización y globalización (p. 56).

Lo anterior manifiesta el valor emocional y el significado que tiene para los jóvenes el hecho de pertenecer a una barra de fútbol y la interiorización de conceptos que dan cuenta de esa filiación al colectivo social al cual pertenecen; esto los define con un "estilo de vida", los diferencia de otras personas al mostrar que no son "ciudadanos comunes", sino personas con pensamientos y comportamientos diferentes. De esta manera, se identifica la capacidad de estos jóvenes de diferenciarse de otro tipo de grupos; ejemplo de ello es "La adopción de himnos y cánticos adaptados a las particularidades de sus equipos y los cuales interpretan antes durante y después del encuentro deportivo, definen otro aspecto de distinción de estas barras" (Gómez, 2008, p. 4).

Los anteriores son aspectos que se configuran, como se pudo evidenciar en esta investigación, al otorgar una relevancia notoria a ciertas herramientas y actitudes que pueden ser relacionadas con rituales y símbolos comunes que permiten identificar su identidad colectiva. Muchos de éstos pueden vincularse no sólo con su forma de vestir, sino también con su manera de pensar, de actuar y comportarse, así como también las territorialidades que se generan en el proceso de distinción de los miembros de otros grupos. Estas prácticas se van incorporando en sus modos de ser tanto individuales como colectivos, antes, durante y después de un partido de fútbol, incluso cuando no hay fútbol. 
Como indican Mercado, Hernández y Alejandrina (2010) "las comunidades van creando a lo largo de su historia, símbolos y rituales, que en su conjunto forman entramados simbólicos, con enorme densidad semántica, por medio de los cuales comunican a los demás su forma de pensar y de ser" (p. 245). Esto se relaciona, además, con los espacios de socialización a los que los jóvenes asisten, ya que no sólo se limita al estadio de fútbol, sino además al barrio donde viven y los sitios estratégicos que frecuentan para compartir sus similitudes, lo que también nutre los comportamientos territoriales de estos jóvenes que los diferencia o que los enmarca.

La simbología que identifica a estos jóvenes está ligada principalmente al equipo de fútbol. Objetos tales como camisetas, banderas, gorros, manillas y otros, hacen parte de la indumentaria que identifica a los jóvenes pertenecientes a una barra. La mayoría de los objetos de la barra y de los barristas, como las banderas, los tambores, las sombrillas, la indumentaria y los tatuajes son símbolos de identidad de la barra y se utilizan en las zonas barristas como lenguaje no verbal que marca el territorio y expresa identidad de grupo. Los objetos de propiedad colectiva llevan símbolos barristas dirigidos al interior y al exterior de la barra, como es el caso de los nombres de los parches, de las banderas del equipo de la ciudad, etc. (Clavijo, 2010).

Como afirma Moreira (2007) "los hinchas ponen en juego un conjunto de prácticas de aliento y apoyo que denotan, además de una fuerte pasión por su cuadro de fútbol, una manifiesta hostilidad" (p. 2). Es decir, todas las prácticas asociadas al apoyo fervoroso a su equipo de fútbol y a los ideales del barrista hacen parte de los rituales y símbolos que incorporan a dichas prácticas. Además "las barras, adentro del estadio, son un lastre viviente que arrastra la civilización desde los tiempos del caníbal tatuado, perforado y celoso de su territorio" (García y López, 2000, p. 47), se distinguen de otros por sus comportamientos y su apariencia, ya que esta se forja de acuerdo con los ideales de los jóvenes, las creencias y sobre todo la construcción de dicha identidad social.

Dentro del estadio y en otros espacios se diferencian por dichas apariencias físicas que se observan; los tatuajes y la indumentaria, entre otros elementos, son los principales símbolos, lo cual evidencia que esta identidad colectiva es estructurada y contiene no sólo intersubjetividades similares con respeto a un equipo de fútbol, sino también, prácticas, música, comportamientos, rituales, símbolos y demás elementos que integran el ser barrista. También: 
La identidad que se construye alrededor de la banda es inicialmente una identidad territorial y hoy, aunque el perfil de este tipo de bandas ha cambiado, los grupos de jóvenes que se reúnen en las calles como único espacio de socialización entre sí no sólo se han mantenido, sino que han aumentado, aunque ya no se autoproclamen "bandas" como tal (Castillo, 2002, p. 62).

Otro aspecto que integra al sentido de territorialidad, como otra práctica ritual de estos colectivos, es diferenciarse y compararse con otros colectivos con igualdad en ideologías, pero diferente color.

Como se comentaba en un apartado anterior, muchas de estas simbologías se relacionan directamente con elementos vinculados al equipo de fútbol; dentro del estadio, en un partido que tiene un significado tan considerable, los jóvenes estarían dispuestos a dar la vida por las banderas o "trapos". Un ejemplo de ello se da en los partidos de fútbol en los que "Las banderas robadas a la hinchada contraria son conocidas como trofeos de guerra, los que se exponen en la tribuna popular con la intención de humillar a sus propietarios” (Moreira, 2007, p. 11). Esta práctica contiene rituales y simbologías particulares de las barras, ya que la bandera es un símbolo único e irrefutable de la banda y uno de los rituales es robar "trapos" con el fin de humillar o provocar a las barras contrarias, lo mismo sucedería si a la barra le es robada una bandera o trapo. Todas estas características son ligadas a las costumbres y rituales que giran en torno al barrismo y al sentido de territorialidad que se maneja como elemento básico de la identidad colectiva barrista. De esta manera se evidencia que son "Los trapos más valiosos: la anaconda y los frentes de la barra” (Clavijo, 2010, p.126).

Dentro y fuera del estadio también se evidencian prácticas comportamentales encaminadas a alentar al equipo de fútbol. Quien no lo haga será considerado como ajeno al colectivo, pues estas prácticas son las que los identifican según su ideología. Por ejemplo:

La agitación coordinada de los brazos en cada canción, los movimientos hacia los costados, los puños bien altos y, muy especialmente, los saltos armónicos sobre las tribunas componen una serie de elementos claves para establecer la superioridad sobre un rival que es amargo, que no se mueve y que no grita (Gil, 2006, p. 335).

De estos comportamientos asociados para alentar el equipo, también hacen parte los cantos, que son uno de los rituales y símbolos más importantes de los barristas dentro y fuera de los estadios. Y que son explicados por Clavijo (2010) así: 
Desde los orígenes, con los inicios mismos de la barra, los cantos han sido su signo distintivo en el estadio. Los primeros barristas empezaron a diferenciarse de los otros hinchas por la adopción de cantos para animar al equipo. Los cantos originales vinieron de las barras argentinas adaptados por barristas colombianos a la temática local (p.174).

Un factor importante que se constata en las prácticas identitarias de los barristas y que hacen parte de sus rituales y símbolos es el "aguante". En las entrevistas que se realizaron, este término se acentúa como uno de los más importantes y característicos de esta construcción colectiva del ser barristas. "Los hinchas militantes hablan del aguante para referirse al abanico de prácticas que despliegan en nombre del club, al compromiso y a la fidelidad de acompañar al equipo a todos los partidos" (Moreira, 2007, p.8). De esta manera, el "aguante" se convierte, no sólo en el término más característico de este colectivo, sino también en una forma de demostrar el amor por su equipo y la filiación a su grupo. El hecho de pertenecer a una barra se demuestra por medio del "aguante" en el momento que haya que demostrarlo, sea en las riñas entre barras, con cantos, saltos y movimientos corporales que determinan quien sí tiene "aguante" y quién no.

También, el "aguante" lo transmiten hacia los jugadores para que en el momento de un partido, rinda más en el juego. Este "aguante", traducido en cantos, alegatos, movimientos corporales son los que dan "vida" a una tribuna donde todos los jóvenes, envueltos por la pasión de ser hinchas y barristas de un equipo, muestran su entusiasmo incluso hacia la misma barra, más que al propio equipo de fútbol. Muchas veces, este "aguante" lo manifiestan los jóvenes en aras de continuar ocupando un espacio en dicho colectivo, bien sea mostrando que quieren pertenecer a éste a como dé lugar, ya que hace parte de sus ideales o porque dicho colectivo le ofrece lo que siempre ha esperado, realzando los aspectos positivos que nutren cada vez más esa pasión.

Así mismo, indican Garriga y Alabarces (2008) que el "aguante" es el principal de los bienes simbólicos y remite al plano de la violencia en su dimensión de enfrentamiento. Ya que sólo en una lucha, en una acción donde se ejerce violencia de hecho y no simbólica se puede probar la posesión del "aguante". Este bien engloba saberes de lucha corporal, de resistencia al dolor y de carencia de temor al riesgo. Estos saberes y formas de actuar sólo pueden ser probados en una contienda corporal, el cuerpo disputa el "aguante". 
Otros elementos que hacen parte de los rituales de estos jóvenes es el consumo de sustancias psicoactivas. Dicha característica se muestra como una pauta de comportamiento generalizada, aunque algunos jóvenes decidan no consumir de ninguna manera, es el alcohol una herramienta de socialización, de creación de lazos de fraternidad y de pertenencia a la barra. "Así, el consumo de alcohol suele estar enmarcado en instancias comunitarias que consagran la amistad (especialmente entre varones jóvenes) más allá de la calidad y el gusto de lo que se beba" (Gil, 2006, p. 344).

El presente trabajo, motivado por una docente y madre de un joven barrista de Manizales, se propuso comprender el mundo social del fútbol a través de las categorías sobre identidades, vinculaciones, los rituales y símbolos surgidos de las prácticas de estos jóvenes. De ahí, se originó la incógnita respecto al papel y la relevancia que tiene para los jóvenes la construcción de una identidad colectiva en relación con las pautas de comportamiento, rituales, símbolos, subjetividades e intersubjetividades que nutren la idea de ser barrista y que los mueve a pertenecer a dichos grupos.

La pertinencia de esta investigación radica en su actualidad; en cuanto es una temática que pese a ser interés de un grupo particular de la población colombiana, su masificación y práctica tienen consecuencias en la sociedad.

\section{Metodología}

Es una investigación de tipo mixto: cualitativo y cuantitativo. Para efectos de este escrito se trabaja sobre la dimensión cualitativa, aunque el proyecto pretende alcanzar los niveles tanto descriptivos y comprensivos; es decir, busca explicar aspectos de patrones del comportamiento humano y de la persona frente a la sociedad. El diseño metodológico es de tipo, etnográfico; esto es, "describe las múltiples formas de vida de los seres humanos” (Martínez, 1994, p. 10); ello, significa que analiza el modo de vida de un grupo de individuos, mediante la observación de sus prácticas, comportamientos y relaciones entre sí y busca captar el sentido que le dan a sus actos y al mundo que les rodea. Esto, con el fin de describir sus creencias, motivaciones y perspectivas y cómo varían de acuerdo con sus circunstancias (Murillo y Martínez, 2010).

En este estudio, entonces, se utilizaron dos técnicas: 1) grupo focal (Barbour, 2007; Hamui y Varela, 2012); y 2) entrevista abierta con instrumentos tales como la guía de grupo focal y la guía de entrevista abierta, que generan una 
comunicación multidimensional, dialéctica y hermenéutica. Simultáneamente a través de la observación de las prácticas en el medio "barrista" se registró la información en diarios de campo (Martínez, 2007). Herramienta que permitió sistematizar las experiencias para su posterior análisis.

La unidad de análisis del proyecto es el mundo social de fútbol, la cual se operó a través de las siguientes categorías: género: masculinidad y feminidad, cuerpos subjetividades y movimientos, identidades y vinculaciones, estigmas y emblemas, territorialidades, ritmos rituales y simbología, tiempos, movimientos emocionales, orden social racionalidades.

Durante tres años y medio, se realizaron trabajos de psicología educativa, social y clínica con jóvenes barristas de la ciudad en los que se obtuvo la información necesaria para la construcción de un proyecto que abordara las categorías de identidades y vinculaciones, así como la de rituales y símbolos que nacen del proyecto.

Ahora, la unidad de información fue constituida por los siguientes actores: funcionarios de la alcaldía, empresarios, periodistas, futbolistas, parejas hijas y madres, policías, hinchas y barristas. Para el caso de este artículo, se presentaron los hallazgos a través de la observación y compilación de información, referida a las categorías de identidades y vinculaciones, ritmos rituales y simbología.

Así mismo, la técnica que se utilizó para el análisis de la información fue la de la construcción de matrices (Hernández, Collado y Baptista, 2010) agregados, iterativos y hallazgos-. La matriz de agregados consiste en agrupar los testimonios comunes sobre una misma temática; la matriz iterativa consiste en agrupar los testimonios divergentes sobre un mismo tema o tópico y la matriz de hallazgos se construye con los testimonios no agrupados en las categorías ni matrices anteriores; con este insumo de información se plantearon los enunciados que condujeron a los hallazgos de la investigación.

En el presente trabajo se muestran además los insumos (testimonios obtenidos en la entrevista y prácticas evidenciadas en los diarios de campo) recogidos en la investigación, a través del seguimiento y la observación de la construcción de identidad de los jóvenes, basada en un colectivo que los mueve desde sus prácticas, símbolos, rituales, filiaciones, y también de la importancia que crean estos jóvenes hacia su grupo de amigos, su "parche", su barra y su amor por un equipo de fútbol. Los resultados permitieron ampliar y profundizar 
la perspectiva sobre el mundo social del fútbol y la comprensión de las prácticas identitarias de los jóvenes.

\section{Resultados}

Las barras de fútbol son grupos sociales que tienen características símiles a las llamadas "tribus urbanas" o "culturas urbanas". Los jóvenes se ven influenciados o movidos por ciertas características del contexto agradables a sus convicciones y subjetividades, sobre todo en esa etapa de construcción de su identidad. Un ejemplo de ello se evidencia en los comentarios de los jóvenes con quienes se realizaron los grupos focales; en su discurso expresaron la igualdad en sus pensamientos frente a términos relacionados con el fútbol y la barra:

- Hombre/Barrista/ Grupo focal: "es alentar y cantar en todos lados... eso es tener aguante, sudarla toda. Aguantar siempre”.

- Hombre/Barrista/grupo focal: "más de los 90... dejar todo en la cancha, alentar al equipo y a los jugadores".

- Hombre/Barrista/grupo focal: "salir sin voz del estadio".

- Hombre/barrista/grupo focal: "es la pasión de cada uno que nos hace ir al estadio y desgarrar la garganta, y nos motiva saber que si el equipo gana es por el aliento del hincha también”.

De igual manera, se evidenciaron otras características ligadas a la identidad de los jóvenes en relación con los rituales que adquieren en dicha agrupación. Tales características se muestran al momento de indagar por conceptos relacionados con el equipo al que siguen y la barra a la que pertenecen; por ejemplo, hacia la idea de lo que representa el equipo y pertenecer a una barra:

- Hombre/Barrista/grupo focal: "un sentimiento, los trapos son la esencia, el trabajo y los sacrificios, nosotros tenemos que esforzarnos para que un trapo llegue a otra tribuna, son sacrificios que digamos los papás, la ciudad, el equipo lo vea y sepa que eso lo hicimos nosotros y todo lo que tuvimos que hacer para que llegue hasta allá, el amor al equipo y a la camiseta".

- Hombre/Barrista/grupo focal: "un estilo de vida, que usted cuando entra al barrismo no piensa igual que es un ciudadano común, usted ya ve el fútbol de otra manera, no es un deporte cualquiera, sino que ya es como el sentido de su vida, usted ya piensa es en fútbol todo el tiempo, se acaba el partido el domingo y el lunes ya está queriendo volver a ver al Once". 
Por otra parte, los medios de comunicación y el acceso a las tecnologías contribuyen a generar más impacto en los jóvenes y una mayor apertura de información de otros países. En el caso de las barras o el fenómeno del barrismo, surge la necesidad de alentar a un equipo y las subjetividades de los jóvenes se ven atraídas hacia esas maneras de moverse en el espacio social del fútbol como seres que le dan vida al espectáculo y que a su vez encuentran una razón de ser en éste. Sánchez (2010), explica al respecto que:

En primer lugar, el concepto de culturas juveniles puede ser utilizado para describir las formas de vida y visiones del mundo características y distintivas de aquellos grupos identificados fundamentalmente por la posición dentro del ciclo vital y la generación social de su componente (p. 126).

Es allí donde se converge con el tipo de población que se acerca a dichas prácticas y al colectivo social, por la etapa generacional en la cual se encuentran, como fue explicado en apartados anteriores. La juventud se ve atraída por tales y por otro tipo de culturas urbanas del medio. Entonces, es la subjetividad de cada individuo la que permite afianzar sus lazos con un colectivo para dejarse permear por las costumbres y movimientos de una cultura que le es atractiva, principalmente en la búsqueda de su identidad individual. Además, como se explicó, tanto el colectivo social como el mismo joven aportan a la construcción de una identidad individual y colectiva.

Otro aporte que se logra hace referencia a las prácticas de las barras; "estos grupos siguen hábitos comunes, apropiándose de lugares y espacios de la ciudad para realizar sus rituales y prácticas" (Sánchez, 2010, p. 127). Además, "las prácticas del lenguaje, los rituales de consumo cultural, la vestimenta, al presentarse como diferentes y en principio críticas, han sido mostradas como evidencias del contenido liberador de las culturas juveniles" (Sánchez, 2010, p. 127). Un ejemplo de lo anterior es el "trapo" que hace parte fundamental de sus rituales y símbolos más significativos:

- Hombre/barristas/grupo focal: "el trapo en sí como usted decía, es el alma del parche, es lo que el parche la barra hace lo que sea por ese trapo".

- Hombre/barritas/grupo focal: "el trapo, el trapo es un amor porque usted representa su cancha, su barra, su barrio, comprar la tela, cocerla, pintarla y echar con ese trapo para todas partes, muchos parceros que ya lo han tenido ya no están, el trapo lo es todo". 
Otro término relacionado con las prácticas barristas, es el "aguante", definido como símbolo de su identidad colectiva, definido por algunos jóvenes como:

- Hombre/Barrista/grupo focal: "el aguante es uno ir a cantarle al equipo, alentar al equipo, que el equipo lo sienta a uno y que se motiven a jugar, por ejemplo, en este momento el equipo no quiere jugar y nosotros le estamos pidiendo huevos para que jueguen, porque a nosotros nos duele que el equipo este mal".

- Hombre/Barrista/grupo focal: "expresar todo lo que sentimos por el equipo mediante un canto y aguantar para que el equipo sienta”.

Además se evidencia, implícito el tema de los lugares y espacios (territorialidades) que ocupan estos jóvenes como el estadio, los barrios y lugares estratégicos de encuentro; asimismo, la indumentaria característica y los símbolos representativos tales como los objetos propios de la barra, alusivos al equipo de fútbol. De esta manera se constatan las prácticas de "las juventudes urbanas, de una ciudad y los referentes que buscan los jóvenes para sentirse identificados, para sentirse parte de algo" (García y López, 2000, p. 113).

Finalmente, el estudio da cuenta y confirma la importancia que tiene este colectivo para la sociedad en general y la influencia ejercida principalmente en la población joven. Es un contexto donde el fútbol se ha convertido no sólo en un deporte sino también en un estilo de vida, para aquellos chicos que están en plena construcción de identidad individual y buscan un motivo para vivir.

\section{Conclusiones}

El lenguaje universal presente en el fútbol, considerado como el deporte popular y de más fácil acceso, es una cultura apropiada por los barristas y que manifiestan en sus prácticas comunes; un lenguaje que configura una carga simbólica y que, no obstante, tiene la función de relacionar de forma directa los hechos futbolísticos, logrando aumentar la cantidad de adhesiones de quienes se consideran militantes de las barras de fútbol. Este acontecimiento permite pensar el fenómeno del barrismo como subdivisión de las tribus urbanas, enfoques sociales que permiten participación, identidad y afinidad a partir de contextos, lugares e imaginarios sociales.

En la actualidad, las estéticas, ideologías y formas de proceder de un barrista, determinan un comportamiento común, no excluyente de los miembros de las 
barras. Maffesoli (citado por Sánchez, 2010) explica que las barras se relacionan con los reagrupamientos juveniles que surgieron en los grandes centros urbanos y que son las nuevas formas de relaciones socioculturales calificadas como "neotribalismo", caracterizado por la fluidez, la asociación puntual, la dispersión y la fragmentación. Estos jóvenes pertenecientes a las barras se diferencian de otros grupos de la sociedad; es decir, se definen, tienen ideales, pensamientos, sentimientos, comportamientos que los caracterizan y sobre todo sienten una fuerte necesidad de ser reconocidos ante el contexto que los rodea.

La violencia también se ha mostrado como una característica fundamental desde dichos grupos o barras, manifestada en la lucha, la resistencia al dolor y la carencia de temor al riesgo.

Sobre la identidad, como categoría, se concluye que la estructura de las barras de fútbol es más compleja de lo que parece, ya que dichas agrupaciones tienen sus propias maneras de comunicarse y posicionarse en el contexto, así como sus rituales y simbologías características que las diferencian de otros colectivos sociales. Se logra identificar, que para un buen número de estos jóvenes, la necesidad de pertenecer a "algo" en este caso una barra, es una consecuencia de factores sociales como carecer de oportunidades académicas, recreativas, culturales, entre otras; en la barra encuentra sujetos en sus mismas condiciones.

Respecto la construcción de identidad colectiva de estos jóvenes podría considerarse como una nueva tribu urbana de la sociedad moderna, ligada a una historia de barras europeas y de costumbres argentinas que han nutrido lo que es y significa ser un barrista de un equipo de fútbol.

\section{Referencias}

Alabarces, P. y Garriga, J. (2008). El "aguante": una identidad corporal y popular. Intersecciones en Antropología, (9), 275-289.

Ávila, S. (2008). Laterales. Revista Virtual Universidad Católica del Norte, (25). Recuperado de 2016. http://revistavirtual.ucn.edu.co/index.php/RevistaUCN/article/viewFile/124/242

Barbour, R. (2007). Doing Focus Groups. London: SAGE Publications. 
Bordignon, N. A. (2006). El desarrollo psicosocial de Eric Erickson, el diagrama epigenético del adulto. Revista Lasallista de Investigación, 2(2), 50-63.

Canto, J y Moral, F. (2005). El sí mismo desde la teoría de la identidad social. Universidad de Málaga, España. Escritos de psicología, (7), 50-70.

Castaño, P., Uribe, G. A., y Nicolas, I. (2014). Barras bravas en el fútbol, consumo de drogas y violencia. Medellín, Colombia: Fundación universitaria Luis Amigó.

Castillo, H. (2002). De las bandas a las tribus urbanas. De la transgresión a la nueva identidad social. Desacatos, (9), 57-71.

Clavijo, J. (2010). Cantar bajo la anaconda, un análisis sociocultural del barrismo en el fútbol. Bogotá, Colombia: Pontificia Universidad Javeriana.

Fernández, F. (2004). Fútbol, relaciones asimétricas y poder: los vínculos entre dirigentes, referentes políticos y barras brava. El caso de talleres de perico (Jujuy-Argentina). Revista de Ciencias Sociales (Cl), (14), 95-111.

Galeano, E. (1995). El Fútbol a sol y sombra. México: Editorial Siglo XXI.

García, D. F. y López, L. M. (2000). ¿Un autogol al fútbol? barras bravas de santa fe de Bogotá. Santa fe de Bogotá, D.C: Pontificia Universidad Javeriana.

Garriga, J. A. (2005). Lomo de macho. Cuerpo, masculinidad y violencia de un grupo de simpatizantes del fútbol. Cuadernos de Antropología Social, (22), 201-216.

Garriga, J.A. (2006). Acá es así: Hinchadas de fútbol, violencia y territorios. $R e-$ vista de Antropología, (9), 93-107.

Gil, G.J. (2006). “Te sigo a todas partes”: Pasión y aguante en una hinchada de fútbol de un club del interior. Intersecciones en Antropología, (7), 333-348.

Gómez, G. (2008). $1^{\circ}$ Encontro da Alesde "Esporte na America Latina: atualidade e perspectivas. Barras Bravas: Pasión, agresión, represión. Paraná-Brasil. ALESDE. Recuperado de http://www.alesde.ufpr.br/encontro/trabalhos/27. pdf 
Hamui, A y Varela, M. (2012). La técnica de grupos focales. Metodología de investigación en educación médica. Departamento de investigación educativa y médica.

Hernández, R., Collado, C. F. y Baptista. P. (2010). Metodología de la investigación. México: Interamericana editores S.A.

Javaloy, F. (1993). El paradigma de la identidad social en el estudio del comportamiento colectivo y de los movimientos sociales. Psicothema, (5), 277-286.

Londoño, A. M. y Pinilla, V. E. (2009). El Barrismo Social de Hinchas por Manizales. Una práctica política y ciudadana. Revista Austral de Ciencias Sociales, (16), 73-88.

Martínez, L.A. (2007). La observación y el diario de campo en la definición de investigación. Recuperado de: //datateca.unad.edu.co/contenidos/401121/ diario_de_campo.pdf

Martínez, M. (1994). La investigación cualitativa etnográfica en educación. México: Trillas

Medina, F. (2009). El fútbol y la vivencia festiva de la nacionalidad. Razón y Palabra, 14(69).

Meneses, J. A. (2008). El fútbol nos une: socialización, ritual e identidad en torno al fútbol. Culturales, IV (8), 101-140.

Mercado, A y Hernández, A. V. (2010). El proceso de construcción de la identidad colectiva. Convergencia. Revista de Ciencias Sociales, 17(53), 229-251.

Moreira, M. V. (2007). Etnografía sobre el honor y la violencia de una hinchada de fútbol en Argentina. Revista Austral de Ciencias Sociales, (13), 5-19.

Murillo, J y Martínez, C. (2010). Investigación etnográfica. Recuperado de http:/ / www. uam. Es/personal_pdi/stmaria/jmurillo/InvestigacionEE/Presentaciones/Curso_10/I_Etnografica_Trabajo.pdf

Panzeri, D. (2011). Fútbol dinámica de lo impensado. Colombia: Comunicaciones S. A. S. 
Parche. (2015). AsiHablamos.com. Recuperado de http://www.asihablamos.com/ www/significado/palabra/parche.

Sánchez, J. (2010). Jóvenes de otros mundos: ¿Tribus urbanas? ¿Culturas juveniles? Aportaciones desde contextos no occidentales. Cuadernos de Antropología Social, (31), 121-143.

Scandroglio, B., López, J. y San José, M. C. (2008). La Teoría de la Identidad Social: una síntesis crítica de sus fundamentos, evidencias y controversias. Psicothema, 20 (1), 80-89.

Vélez, B. (2011). Fútbol desde la tribuna, pasiones y fantasías. Medellín, Colombia: Sílaba Ed.

Villena, S. (2002). El fútbol y las identidades. Balance preliminar sobre el estado de la investigación en América Latina. Iconos. Revista de Ciencias Sociales, (14), 126-136. 